\title{
Localized recrystallization and cracking of lead-free solder interconnections under thermal cycling - ERRATUM
}

\author{
Hongtao Chen, Maik Mueller, Toni Tuomas Mattila, Jue Li, Xuwen Liu, Klaus-Juergen Wolter,
} and Mervi Paulasto-Kröckel

doi: 10.1557/jmr.2011.197, Published by Cambridge University Press, 16 August 2011.

On the article opening page, the third author's name was incorrectly published as "Tonu Tuomas Mattila."

The correct spelling is Toni Tuomas Mattila.

The publisher regrets the error.

\section{REFERENCE}

H. Chen, M. Mueller, T.T. Mattila, J. Li, X. Liu, K.-J. Wolter, M. Paulasto-Kröckel: Localized recrystallization and cracking of leadfree solder interconnections under thermal cycling. J. Mater. Res. 26(16), 2103 (2011) 